\title{
MHC Interaction
}

National Cancer Institute

\section{Source}

National Cancer Institute. MHC Interaction. NCI Thesaurus. Code C40519.

$\mathrm{MHC}$ Interaction involves temporary non-covalent binding of a molecule through

intermolecular physical forces of attraction with protein complexes on the surface of diverse cell types that typically mediate cellular cooperation in the immune response. 